\title{
Program promotif poskestren terhadap PHBS santri di pondok pesantren
}

\author{
Lalu Dedy Supriatna ${ }^{1 *}$, Indasah², Byba Melda²
}

1Stikes Yarsi Mataram. * Email: dedybelmon@gmail.com)

${ }^{2}$ Institute of Health Sciences Surya Mitra Husada Kediri

\author{
Abstract \\ Pesantren Health Post (Poskestren) promotional program for Clean and Healthy Living Behavior (CHLB) \\ among students at Islamic boarding schools
}

Background: Clean and Healthy Living Behavior (CHLB) school environment structure is an effort to empower students, teachers, and the school community to know, want, and be able to treat CHLB. This is in line with Health Promotion in educational institutions (Health Promoting School) launched by the World Health Organization which uses a holistic model that includes the relationship between physical, mental, social and environmental aspects.

Purpose: To analyze the influence of the health post promotion program for Clean and Healthy Living Behavior (CHLB) among students at Islamic boarding schools

Method: An observational analytic study using a cross sectional approach. The sampling technique used simple random sampling, a sample of 271 respondents. The research instrument used a questionnaire with 20 question items. The data analysis technique used the chi-square test.

Results: Obtained from 271 respondents with the Poskestren program (Promotive) in the less category, it will have an influence in the moderate category on the (CHLB) of students $(36.16 \%)$. It is necessary to plan that is directed and sustainable in improving the quality for the implementation of the poskestren program in a promotional manner so that it can get better results.

Conclusion: The Pesantren Health Post program promoted a significant effect on (CHLB) among students at Ad Diinul Qayyim Islamic Boarding School, West Lombok Regency, NTB.

Keywords: Pesantren Health Post (Poskestren); Promotional program; Clean and Healthy Living Behavior (CHLB); Students; Islamic boarding schools

Pendahuluan: Perilaku Hidup Bersih dan Sehat (PHBS) tatanan lingkungan sekolah adalah upaya untuk memberdayakan siswa, guru, dan masyarakat lingkungan sekolah agar tahu, mau, dan mampu memperlakukan PHBS. Hal ini sejalan dengan Promosi Kesehatan di institusi pendidikan (Health Promoting School) yang dicanangkan oleh Organisasi Kesehatan Dunia yang menggunakan model holistik yang meliputi hubungan antar aspek fisik, mental, sosial, dan lingkungan.

Tujuan: Untuk menganalisis pengaruh program promotif poskestren terhadap PHBS Santri di Pondok Pesantren Metode: Penelitian analitik observasional dengan menggunakan pendekatan cross sectional. Teknik sampling menggunakan simple random sampling, sampel sebanyak 271 responden. Instrumen penelitian menggunakan kuisioner dengan 20 item pertanyaan. Teknik analisa data menggunakan uji chi-square.

Hasil: Didapatkan dari 271 responden dengan program Poskestren (Promotif) dalam kategori kurang maka akan memberikan pengaruh dalam kategori cukup pada PHBS santri (36.16\%). Perlu perencanaan yang terarah dan berkesinambungan dalam meningkatkan kualitas untuk penerapan program poskestren secara promotif sehingga mendapatkan hasil yang lebih baik.

Simpulan: Program Poskestren secara promotif berpengaruh secara signifikan terhadap PHBS pada santri di Pondok Pesantren Ad Diinul Qayyim Kabupaten Lombok Barat NTB.

Kata Kunci: Perilaku Hidup Bersih dan Sehat (PHBS); Program Poskestren; Promotif; Santri; Pondok Pesantren 


\section{PENDAHULUAN}

Perilaku Hidup Bersih dan Sehat (PHBS) dilatarbelakangi oleh penetapan visi Indonesia Sehat 2010, Perilaku Hidup Bersih dan Sehat terdiri dari beberapa tatanan yaitu, tatanan rumah tangga, tatanan tempat kerja, tatanan tempat umum, tatanan fasilitas kesehatan dan tatanan lingkungan sekolah (Rorimpandey et al., 2015; Kementerian Kesehatan Republik Indonesia, 2004). Secara nasional, penduduk yang telah memenuhi kriteria PHBS baik tahun 2005 sebesar $27 \%$ meningkat menjadi 40\% di tahun 2015 . Sementara itu target nasional tahun 2019 diharapkan penduduk Indonesia yang memenuhi dapat mencapai angka 80\% (Rorimpandey, et al., 2015).

Perilaku Hidup Bersih dan Sehat (PHBS) tatanan lingkungan sekolah adalah upaya untuk memberdayakan siswa, guru, dan masyarakat lingkungan sekolah agar tahu, mau, dan mampu memperilakukan PHBS (Julianti et al., 2018; Carolina, et al., 2016 ). Upaya promosi kesehatan di pondok pesantren antara lain melalui pendirian pos kesehatan pesantren (Poskestren) dan peningkatan PHBS (Perilaku Hidup Bersih dan Sehat) di sekolah/pondok (Astuti et al., 2016).

Pondok Pesantren merupakan salah satu bentuk lembaga Pendidikan keagamaan yang tumbuh dan berkembang dari oleh dan untuk masyarakat yang berperan penting dalam pengembangan sumber daya manusia, diharapkan para santri dan para pemimpin serta pengelola pondok pesantren, tidak saja mahir dalam aspek pembangunan moral dan spiritual dengan intelektual yang bernuansa agamis, namun dapat pula menjadi motor penggerak, motivator dan inovator dalam pembangunan kesehatan, serta menjadi teladan dalam berperilaku hidup bersih dan sehat bagi masyarakat sekitar (Kementerian Kesehatan Republik Indonesia, 2009; Saputra et al, 2019; Widiyarini, 2019; Evayanti, 2012).

Keberadaan pondok pesantren ditengahtengah masyarakat Indonesia sudah dirasakan manfaatnya sejak dulu. Sejarah perkembangan pondok pesantren tidak lepas dari sejarah bangsa ini dalam meraih kemerdekaan. Seiring perjalanan waktu, kebutuhan akan pondok pesantren yang dapat mengakomodir kebutuhan masyarakat di bidang agama dan pendidikan yang berkualitas sangat dibutuhkan. Dalam upaya mendukung hal tersebut, kebutuhan fasilitas penunjang sangat dibutuhkan. Salah satu kebutuhan tersebut adalah tersedianya sarana pelayanan kesehatan yang memadai (Wahyudin \& Arifin, 2015; Carolina et al, 2016 ).

Pemberdayaan masyarakat di Pondok Pesantren merupakan upaya fasilitasi, agar warga pondok pesantren mengenal masalah yang dihadapi, merencanakan dan melakukan upaya pemecahan dengan memanfaatkan potensi setempat sesuai situasi, kondisi dan kebutuhan setempat (Rifah, 2019). Upaya fasilitasi tersebut diharapkan pula dapat mengembangkan kemampuan warga pondok pesantren untuk menjadi perintis/pelaku dan pemimpin yang dapat menggerakkan masyarakat berdasarkan asas kemandirian dan kebersarnaan (Martino, 2018).

Kegiatan yang dilakukan dalam pengelolaan Poskestren, lebih diutamakan dalam hal pelayanan promotif (peningkatan kesehatan) dan preventif (pencegahan), tanpa mengabaikan aspek kuratif (pengobatan) dan rehabilitatif (pemulihan kesehatan), yang dilandasi semangat gotong royong dengan pembinaan oleh Puskesmas setempat (Evayanti, 2012; Demak, 2013; Sari, 2013).

Untuk meningkatkan derajat kesehatan masyarakat lingkungan pondok pesantren perlu adanya upaya untuk meningkatkan pengetahuan santri tentang kesehatan secara umum, sehingga diharapkan ada perubahan sikap serta diikuti dengan perubahan perilaku kebersihan perorangan (Zakiudin \& Shaluhiyah, 2016). Upaya yang dilakukan untuk meningkatkan pengetahuan dan kesadaran masyarakat pondok pesantren salah satunya dapat dilakukan melalui upaya promosi kesehatan (Putri, \& Akifah, 2017; Emila \& Prabandari, 2019; Leonita \& Jalinus, 2018).

Guna memfasilitasi para petugas dan pemangku kepentingan (stakeholders) terkait lainnya, perlu adanya pedoman praktis yang dapat dijadikan acuan dalam melaksanakan tugasnya. Melalui Pedoman Penyelenggaraan dan Pembinaan Pos Kesehatan Pesantren (Poskestren) ini, diharapkan dapat dijadikan acuan dalam pembinaan kesehatan di pondok pesantren 
dan upaya menumbuhkembangkan Poskestren (Syam et al., 2018).

\section{METODE PENELITIAN}

Desain penelitian yang digunakan penelitian korelasional dengan menggunakan pendekatan crossectional. Teknik sampling dengan simple random sampling, sampel sebanyak 271 responden. Instrumen penelitian menggunakan kuisioner dengan 20 item pertanyaan dengan nilai maksimum 4 dan nilai minimum 1 untuk setiap item pertanyaan. Hasil uji validitas menunjukkan nilai korelasi yang lebih besar dari pada nilai tabel 0,259 . Dan nilai atau koefisien reliabilitas Alpha sebesar 0,631 . Teknik analisa data menggunakan uji chi-square.

\section{HASIL}

Tabel 1. Karakteristik Demografi Responden ( $\mathrm{N}=271)$.

\begin{tabular}{llccc}
\hline Demografi & & $\mathrm{n}$ & $\%$ & $\mathbf{M} \pm \mathbf{S D}$ \\
& & & & \\
\hline Usia (Tahun)(Rentang: 14-20) & MA & 219 & & $16.71 \pm 0.839$ \\
& MTS & 52 & $13.87 \pm 0.991$
\end{tabular}

Pendidikan

$\begin{array}{lcc}\text { MA } & 219 & 80.8 \\ \text { MTS } & 52 & 19.2\end{array}$

Jenis Kelamin

Laki-laki

Perempuan $\quad 145 \quad 53.5$

$126 \quad 46.5$

Pekerjaan Orang Tua

$\begin{array}{lcc}\text { PNS } & 12 & 4.4 \\ \text { Swasta } & 197 & 72.7 \\ \text { Tani/Nelayan } & 62 & 22.9\end{array}$

Lama Mondok

271

$2.82 \pm 1.803$

(Tahun)(Rentang: 0-7)

Penyakit yang Pernah Diderita

\begin{tabular}{llcc} 
& Muntaber & 4 & 1.5 \\
& DB & 2 & 0.7 \\
& Penyakit Kulit & 74 & 27.5 \\
& Diare & 19 & 7.0 \\
& Thypoid & 4 & 1.5 \\
& Panu & 2 & 0.7 \\
& Lain-lain & 14 & 5.2 \\
& Tidak Ada & 152 & 56.1 \\
& & & \\
Program Poskestren & Kurang & 171 & 63.1 \\
(Promotif) & Cukup & 99 & 36.5 \\
& Baik & 1 & 0.4 \\
& & & \\
& Kurang & 2 & 0.7 \\
& Cukup & 182 & 67.2 \\
& Baik & 87 & 32.1 \\
\hline
\end{tabular}

Lalu Dedy Supriatna"*, Email: dedybelmon@gmail.com)

Indasah ${ }^{2}$, Byba Melda ${ }^{2}$, Institute of Health Sciences Surya Mitra Husada Kediri 
Berdasarkan tabel 1 Responden berusia 14 sampai 20 tahun responden, duduk di bangku MA 219 (80,8\%), rata-rata berusia 16,71 tahun dengan standar deviasi 0,839, sedangkan untuk santri MTS rata-rata berusia13,87 dengan standar deviasi 0,991 . Berjenis kelamin laki-laki $(53,5 \%)$. Adapun pekerjaan orang tua responden yang terbanyak adalah swasta $(72,7 \%)$. Dilihat dari lama mondok responden dalam rentang 0 sampai 7 tahun dengan rata-rata 2.82 tahun.

Penyakit yang pernah diderita reponden selama mondok sebagian besar $(56,1 \%)$ tidak pernah mengalami/menderita penyakit yang berkaitan dengan PHBS. Sebagian besar responden menilai program Poskestren (Promotif) di Pondok Pesantren dalam kategori kurang $(63,1 \%)$ dan perilaku PHBS pada para santri yang terbanyak dalam kategori Cukup $(67,2 \%)$.

Tabel 2. Tabulasi Silang Program Poskestren (Promotif) Terhadap PHBS Santri

\begin{tabular}{|c|c|c|c|c|c|c|}
\hline \multirow{2}{*}{ Variabel } & & & \multicolumn{3}{|c|}{ Kategori PHBS } & \multirow{2}{*}{ Total } \\
\hline & & & Kurang & Cukup & Baik & \\
\hline \multirow{3}{*}{$\begin{array}{l}\text { Kategori } \\
\text { Program } \\
\text { Promotif }\end{array}$} & Kurang & $\begin{array}{l}\text { Frekuensi } \\
\% \text { dari Total }\end{array}$ & $\begin{array}{l}18 \\
6.64\end{array}$ & $\begin{array}{l}80 \\
29.52\end{array}$ & $\begin{array}{l}16 \\
5.90\end{array}$ & $\begin{array}{l}114 \\
42.07\end{array}$ \\
\hline & Cukup & $\begin{array}{l}\text { Frekuensi } \\
\% \text { dari Total }\end{array}$ & $\begin{array}{l}2 \\
0.74\end{array}$ & $\begin{array}{l}98 \\
36.16\end{array}$ & $\begin{array}{l}46 \\
16.97\end{array}$ & $\begin{array}{l}146 \\
53.87\end{array}$ \\
\hline & Baik & $\begin{array}{l}\text { Frekuensi } \\
\% \text { dari Total }\end{array}$ & $\begin{array}{l}0 \\
0\end{array}$ & $\begin{array}{l}2 \\
0.74\end{array}$ & $\begin{array}{l}9 \\
3.32\end{array}$ & $\begin{array}{l}11 \\
4.06\end{array}$ \\
\hline Total & & $\begin{array}{l}\text { Frekuensi } \\
\% \text { dari Total }\end{array}$ & $\begin{array}{l}20 \\
7.38\end{array}$ & $\begin{array}{l}180 \\
66.42\end{array}$ & $\begin{array}{l}71 \\
26.20\end{array}$ & $\begin{array}{l}271 \\
100\end{array}$ \\
\hline
\end{tabular}

$P$ value $=0.000$

Berdasarkan tabel di atas, sebaran frekuensi kategori program Promotif nampak terpusat pada kelompok "cukup". Namun demikian, pada bagian ini, terdapat sedikit perubahan pada kategori "kurang" dan kategori "baik". Pada Program Promotif kategori "kurang", jumlah kategori PHBS yang "kurang" lebih banyak dibandingkan dengan kategori "baik". Dan pada Program Promotif kategori "baik", tidak terdapat satu pun santri dengan PHBS kurang, dan mayoritas santri pada kategori ini memiliki PHBS dengan kategori "baik", yaitu sebanyak 9 orang.

\section{PEMBAHASAN}

Pengaruh program Poskestren (Promotif dan Preventif) terhadap PHBS didapatkan nilai frekuensi kategori program Promotif nampak terpusat pada kelompok "cukup". Hal ini menunjukkan bahwa terdapat pengaruh yang signifikan pada PHBS santri setelah program Poskestren (Promotif) dimana program Poskestren (Promotif) dinilai cukup oleh santri dengan nilai $(36.16 \%)$. Sehingga dapat disimpulkan ada pengaruh yang signifikan program Poskestren (Promotif) terhadap PHBS santri.

Hasil penelitian ini sejalan dengan penelitian sebelumnya dimana program Poskestren sebagian besar $(58,6 \%)$ berperan cukup baik. Pondok Pesantren merupakan salah satu bentuk lembaga pendidikan keagamaan yang tumbuh dan berkembang dari oleh dan untuk masyarakat yang berperan penting dalam pengembangan sumber daya manusia, diharapkan para santri dan para pemimpin serta pengelola pondok pesantren tidak saja mahir dalam aspek pembangunan moral dan spiritual dengan intelektual yang bernuansa agamis, namun dapat pula menjadi penggerak motivator dan inovator dalam pembangunan kesehatan, serta menjadi teladan dalam berperilaku hidup bersih dan sehat bagi masyarakat sekitar. Pondok Pesantren telah tumbuh dan berkembang hampir diseluruh daerah,maka diharapkan kegiatan ini dapat menyebar secara merata di seluruh Indonesia (Ikhwanudin, 2013). 


\section{SIMPULAN DAN SARAN}

Program Poskestren secara promotif berpengaruh secara signifikan terhadap PHBS pada santri di Pondok Pesantren Ad Diinul Qayyim Kabupaten Lombok Barat NTB. Diperlukan perencanaan yang terarah dan berkesinambungan dalam meningkatkan kualitas untuk penerapan program poskestren secara promotif sehingga mendapatkan hasil yang lebih baik.

\section{DAFTAR PUSTAKA}

Astuti, R., Mifbakhuddin, M., Nurullita, U., Dyah Larasaty, N., \& Bima Prasetio, D. (2016). Promosi kesehatan, perilaku hidup bersih dan sehat di pondok pesantren.

Carolina, P., Carolina, M., \& Lestari, R. M. (2016). Hubungan tingkat pengetahuan dan sumber informasi dengan penerapan perilaku hidup bersih dan sehat (phbs) pada keluarga di wilayah kerja pustu pahandut seberang kota palangka raya tahun 2016. EnviroScienteae, 12(3), 330-337.

Demak, D. L. K. (2013). Analisis penyebab perilaku aman bekerja pada perawat di RS Islam Asshobirin Tangerang Selatan tahun 2013.

Emilia, O., \& Prabandari, Y. S. (2019). Promosi kesehatan dalam lingkup kesehatan reproduksi. UGM PRESS.

Evayanti, N. P. (2012). Persepsi Siswa SMP dalam Penerapan PHBS Tatanan Sekolah di Kelurahan Tugu dan Pasir Gunung Selatan Kota Depok. Universitas Indonesia.

Ikhwanudin, A. (2013). Perilaku Kesehatan Santri:(Studi Deskriptif Perilaku Pemeliharaan Kesehatan, Pencarian dan Penggunaan Sistem Kesehatan Dan Perilaku Kesehatan Lingkungan Di Pondok Pesantren Assalafi Al Fithrah, Surabaya). Jurnal Sosial dan Politik, 2(2), 3.
Julianti, R., Nasirun, M., \& Wembrayarli, W. (2018). Pelaksanaan Perilaku Hidup Bersih dan Sehat (Phbs) di Lingkungan Sekolah. Jurnal IImiah Potensia, 3(2), 76-82.

Kementerian Kesehatan Republik Indonesia. (2004). Sistem Kesehatan Nasional. Diakses dari:

https://peraturan.bkpm.go.id/jdih/userfiles/batan g/KEPMENKES 131 2004.pdf

Kementerian Kesehatan Republik Indonesia. (2009). Rumah Tangga Sehat dengan Perilaku Hidup Bersih dan Sehat. Diakses dari: http://promkes.kemkes.go.id/wp-

content/uploads/pdf/publikasi materi_promosi/L embar\%20Balik\%20PHBS.pdf

Leonita, E., \& Jalinus, N. (2018). Peran Media Sosial dalam Upaya Promosi Kesehatan: Tinjauan Literatur. INVOTEK: Jurnal Inovasi Vokasional dan Teknologi, 18(2), 25-34.

Martino, P. D. (2018). Upaya pondok pesantren dalam meningkatkan nilai-nilai keagamaan di pondok pesantren sulaiman gandusari trenggalek.

Putri, A. T., \& Akifah, A. (2017). Efektifitas Media Audio Visual Dan Leaflet Terhadap Peningkatan Pengetahuan, Sikap Dan Tindakan Tentang Pencegahan Penyakit Gastritis Pada Santriwati Di Pondok Pesantren Hidayatullah Putri Dan Ummusshabri Kota Kendari Tahun 2017. (Jurnal IImiah Mahasiswa Kesehatan Masyarakat), 2(6)

Rif'ah, E. N. (2019). Pemberdayaan Pusat Kesehatan Pesantren (Poskestren) Untuk Meningkatkan Perilaku Hidup Bersih Dan Sehat. Warta Pengabdian, 13(3), 96-105.

Rorimpandey, H. M., Rattu, A. J. M., \& Tumuraang, M. N. (2015). Faktor-faktor yang berhubungan dengan perilaku hidup bersih dan sehat (PHBS) pada siswa di SMP Negeri 2 Tompaso. Tumou Tou, 1(2). 
Saputra, R., Rahayu, W., \& Putri, R. M. (2019). Hubungan perilaku hidup bersih dan sehat (PHBS) dengan timbulnya penyakit scabies pada santri. Nursing News: Jurnal Ilmiah Keperawatan, 4(1).

Sari, E. R. (2013). Gambaran Higiene dan Sanitasi Kantin Sekolah (Studi Banding SMPN Perkotaan dan SMPN Pedesaan) Tahun 2013 (Doctoral dissertation, Universitas Islam Negeri Alauddin Makassar).

Syam, N., Gafur, A., \& Hamzah, W. (2018). PkM Pengembangan Pos Kesehatan Pesantren (Poskestren) Di Yayasan Wakaf Umi Pesantren Wihdatul Ulum Desa Bontokassi, Kec. Parangloe, Kab. Gowa Tahun 2017. Jurnal Balireso: Jurnal Pengabdian pada Masyarakat, 3(1).
Wahyudin, U., \& Arifin, H. S. (2015). Sosialisasi Sanitasi Diri dan Lingkungan di Pesantren Salafi Melalui Pos Kesehatan Pesantren (Poskestren) Dalam Membentuk Sikap Santri Terhadap Sanitasi. Jurnal kajian komunikasi, 3(2), 148-153.

Widyarini, H. (2019). Perilaku Wanita Dengan Status Perceraian Dalam Penerapan 2 Indikator PHBS: Melakukan Aktivitas Fisik Setiap Hari dan Tidak Merokok di Dalam Rumah.

Zakiudin, A., \& Shaluhiyah, Z. (2016). Perilaku kebersihan diri (personal hygiene) santri di pondok pesantren wilayah Kabupaten Brebes akan terwujud jika didukung dengan ketersediaan sarana prasarana. Jurnal Promosi Kesehatan Indonesia, 11(2), 64-83. 